\title{
POLITTIK EKONOMIK KURAM
}

E-ISSN: 2587-2567

https://dergipark.org.tr/tr/pub/pek

Doi: $10.30586 /$ pek.808117

2020, Cilt 4, Sayı 2, 296-309

Makale Geliş Tarihi: 09.10.2020

Makale Kabul Tarihi: 08.11.2020

Araştırma Makalesi

Türkiye Dijital Oyun Sektöründe Nitelikli İşgücü Sorunsalı: Sosyo-Ekonomik Bir Bakış

Emek Barış KEPENEK ${ }^{1}$

\section{Skilled workforce problem in digital gaming sector of Turkey: A Socio-economic overview}

\begin{abstract}
Digital game is an economic value that has been constantly growing in recent years. With the help of technology, it has also become one of the crucial parts of our social and cultural life. The production process of a digital game bring together many different disciplines such as game design, narrative, programming or marketing). Those disciplines require different kind of skills.

Although the gaming industry started to develop with the new millennium in Turkey, main improvements appeared in 2010s. Most of the companies were established in those years. It can be observed that the firms can be considered as micro sized enterprise since they employ around 10 people on average. The public/private researches show that the digital gaming industry are constantly developing; but, there are also some serious structural problems. One of them is the shortage of skilled workforce. Besides, this problem is also indicated in various National Vision workouts and Development Plans. The aim of this article is to discuss some policy ideas in order to solve that problem. For this purpose, in-depth interviews were made with 30 companies which are the members of Turkish Game Developers Association (TOGED).

To be able to benefit from multi-faceted impacts of digital gaming industry like high trade potential and improving the quality of workforce, specific policy ideas must be designed. Despite, many researches have been made to analyze the social, cultural and economic effects of digital improvements, the concept of digital gaming is neglected.
\end{abstract}

Keywords: digital game, skilled workforce, national education policy

Jel Codes: J24, O38, M13, I25

Öz

Dijital Oyun sektörü son yıllarda sürekli büyüme içerisinde olan bir ekonomik değerdir. Teknolojinin yardımıyla sürekli gelişim göstermiş ve böylece sosyo - kültürel yaşamımızın da en önemli parçalarından bir tanesi olmuştur. Dijital oyun üretim süreçleri çok farklı disiplinleri (oyun tasarımı, anlatı, programlama, pazarlama... vb.) bir araya getirir. Bu farklı disiplinler için farklı nitelikte vasıflar gerekmektedir.

Türkiye dijital oyunlar 2000'li yıllarla üretilmeye başlanmış olsa da ekonomik kazanç, firma sayısındaki artış vb. başarılar 2010 sonrasında elde edilmeye başlanmıştır. Oyun sektöründeki firmaların birçoğu bu yıldan sonra kurulmuştur. Şu anda Türkiye'de yaklaşı 240 firma vardır ve birçoğu mikro ölçekli, ortalama olarak 10 kişi civarında çalışanın istihdam edildiği işletmelerdir. Son 10 yılda yapılan araştırmalar dijital oyun firmalarının sürekli gelişmekte olduklarını gösterse de birçok yapısal problemin varlığını da ortaya koymuşlardır. Bunlardan en önemlisi nitelikli işgücü eksikliğidir. Öte yandan, Türkiye'nin çeşitli vizyon ve planlama çalışmalarında, özellikle bilgi teknolojileri alanında nitelikli çalışanlara duyulan ihtiyaç vurgusunun da altı çizilmektedir. Bu makalenin amacı da sektörün en büyük problemine yönelik olarak çözüm önerileri geliştirmektir. Bunun için, Türkiye Oyun Geliştiricileri Derneği'ne üye (TOGED) 30 firma ile yapılan derinlemesine görüşmeler yapılmıştır.

Dijital oyun sektörünün çok yönlü ve döviz kazandırıcı niteliklerinden faydalanmak için Türkiye'deki sektör yapısının ortaya çıkarılması ve özellikle de nitelikli işgücünün sayısını ve kalitesini artırmak adına özgün politikaların tasarlanması gerekmektedir. Her ne kadar dijitalleşmenin sosyal, kültürel ve ekonomik etkileri üzerine birçok araştırma yapılsa da, dijital oyun sektörünün sosyo-ekonomik durumu gibi niş alanlardaki araştırmaların sayısı yok denecek kadar azdır. Bu bağlamda Türkiye'deki eksikliğin giderilmesine katkı yapılmak da amaçlanmıştır.

Anahtar Kelimeler: dijital oyun, nitelikli işgücü, ulusal eğitim politikası

${ }^{1}$ Dr. Öğr. Üyesi, Başkent Üniversitesi Sosyoloji Bölümü, E-posta: ebkepenek@baskent.edu.tr, ORCID:

https://orcid.org/0000-0002-0086-4867 


\section{Giriș}

İnsanlık tarihi kadar eski olan oyun kavramı, dijital teknolojilerdeki devrim sayılabilecek değişimlerle birlikte ekonomik bir güç kazanmış, kültürel endüstrinin en değerli metalarından biri haline gelmiştir. Farklı platformlarda çok değişik içeriklerle sunulan dijital oyunlar, insanlara bir hizmet olarak ekonomik dürtüler içerisinde sunulmaya başlanmıştır.

Dijital teknolojideki devrimsel değişimler ve internetin hayatımıza girmesi, dijital oyunları çok güçlü ve küresel bir endüstri haline gelmiştir. Dijital oyunlar sadece eğlence sektörünün çok değerli bir üyesi haline gelmemiş; artık firmalar için bir pazarlama aracı ya da okullarda eğitim kalitesini arttırmak için bir materyal veya film endüstrisinin bir parçası olarak kullanılmaya başlanmıştır. Hâlihazırda, dünyada ekonomik açıdan en hızlı büyüyen sektörlerden bir tanesidir. Sektörün 2020 yılında küresel ölçekte büyüklüğünün 160 milyar doları geçmesi beklenmektedir (Newzoo,2020).

Türkiye'de ise dijital oyunların tarihi 1990'larla başlamış, 2000'li yıllarla beraber yükselişe geçmiştir. Ancak 2010'lu yılların ikinci yarısı itibariyle dünya pazarında adından söz ettirmeye başlamıştır. TOGED verilerine göre, 2019 yılında Türk Oyun firmalarının ihracat rakamları 1 milyar dolar sınırını aşarak büyük bir başarı elde etmiştir (www.toged.org). 2012 yılında bu rakam 464 milyon dolardı (Tüdof, 2012). Son 2 yıl içerisinde gerçekleşen yabancı firmaların Türk oyun şirketlerini satın almaları ülkede sektörün kısa sürede geldiği başarılı noktayı gösteren çok önemli başarı hikâyesidir.

Dijital oyun geliştirme süreci ise çok farklı uzmanlık alanlarının bir araya gelmesini gerektiren zorlu bir süreçtir. Oyun tasarımından programlamaya, test aşamasından pazarlamaya çok değişik nitelikte vasıflı işgücü gerektirir. Sadece dijital oyunlar için değil, enformasyon toplumu (Castells, 2011) dönüşümünden ya da dijitalleşme etkisiyle dönüşen tüm sosyal, kültürel ve ekonomik etkileşimlerden olumlu bir şekilde faydalanmak için farklı uzmanlık alanlarında yetişmiş işgücü ihtiyacı her geçen gün artmaktadır.

Türkiye'nin 2023 hedefleri doğrultusunda hazırlanan 10. ve 11. Kalkınma Planlarında Türkiye'nin üretim ve ihracatta yüksek katma değerli ve teknoloji yoğun bir yapıya kavuşması için yapısal bir dönüşüm ihtiyacı bulunduğu belirtilmektedir. Mobil uygulama ve dijital oyunlarda erken aşama girişimlerin arttığ 1 vurgusu yapılarak bu çalışmaların desteklenmesi ve özellikle de bilgi teknolojileri alanında nitelikli çalışanlara ve özellikle yazılım alanında faaliyet gösteren firmaların ölçek büyüterek yurt dışı pazarlara açılmasını sağlayacak etkin politikalara olan ihtiyacın vurgusu yapılmaktadır. Ayrıca, son 10 yılda sektörle ilgili yapılan kamu ya da özel sektör araştırmalarının tamamında, Türkiye'de dijital oyun sektörünün en önemli sorununun nitelikli işgücü eksikliği olduğu belirtilmektedir (ODTÜ TEKNOKENT,2012; AKA, 2016; BTK, 2017; Kepenek 2018). Farklı dönemlerde yapılan çalışmalarda aynı konunun sürekli vurgulanıyor olması Türkiye'nin bu alanda yeterli adımları atmadığını göstermektedir. Bu makalede amaç; Türkiye'de dijital oyun sektöründe faaliyet gösteren firmaların işgücü profilini çıkarmak, temel ihtiyaç alanlarını belirlemek ve bu problemlere yönelik olarak siyasal önerileri geliştirmektir.

Araştırma için TOGED üyesi tüm geliştirici firmalarla hem yüzyüze hem de internet ortamında görüşmeler yapılmıştır. Firmaların yapıları ortaya çıkarılmış, işbirlikleri, ar-ge/inovasyon ve insan kaynağı süreçleri incelenmiştir. Derinlemesine görüşmelerle sektörün genel görünümü ortaya konmuş ve çözüm önerileri geliştirilmiştir. 
Dijital oyun sektörünün çok yönlü ve döviz kazandırıcı niteliklerinden faydalanmak için Türkiye'deki sektör yapısının ortaya çıkarılması ve özellikle de nitelikli işgücünün sayısını ve kalitesini artırmak adına özgün politikaların tasarlanması gerekmektedir. Bilgi iletişim teknolojileri sektörlerinde sayısız araştırmanın ve projenin bulunduğu ülkemizde, dijital oyun sektörünün sosyo-ekonomik durumu gibi niş alanlardaki araştırmaların sayısı yok denecek kadar azdir.

\section{Dijital Oyun Üretim Süreci ve İşgücü İlişsisi}

Dijital oyun, bir ya da birden fazla oyuncunun elektronik bir ortamda klasik oyun edinimlerini gerçekleștirmesi olarak tanımlayabiliriz. (Bryce ve Rutter, 2006; Bergonse, 2017). Klasik bir oyundaki özgürlük ve kendine ait dünyanın varlığg (Huizinga, 2013) aynen burada da geçerlidir. Ancak teknolojinin yardımıyla çok çeşitli dünyalar, senaryolar ve kimlikler sunmaktadır. $\mathrm{Bu}$ sayede de 3 milyardan fazla insanı etkilemiş ve son 10 yılda en hızlı büyüyen bir ekonomik sektör haline gelmiştir. (www.newzoo.com).

Dijital oyunlar bir eğlence aracı olarak görülse de, farklı disiplinlerden yüz binlerce çalışanı barındıran ve her yıl büyüyen ekonomik yapısıyla da bu alanda çalışmak isteyen kişilere istihdam olanakları sunan emek piyasasının önemli alanlardan bir tanesidir. Eğitim, sağlık, savunma sanayii ve hatta sinema gibi farklı sektörlerde oyun teknolojileri kullanılır. Doğası gereği kişisel bilgisayarlar, internet, akıllı telefon, arttırılmış gerçeklik gibi çok farklı teknolojik alanlarda kendine yer edinir. Bu sayede dijitalleşen kültürün en önemli unsurlarından bir tanesi olmaktadır.

\subsection{Dijital oyun üretim süreci ve işgücü}

Dijital dönüşüm ile yapay zekâ, akıllı robotlar, akıllı sistemler, nesnelerin interneti, büyük veri, 3D yazıcılar, zenginleştirilmiş gerçeklik gibi bilgi ve iletişim teknolojilerinin sunduğu firsatlardan yararlanılarak, fiziksel dünyanın gerçekleriyle siber dünyanın yetenekleri ve gücünü birleştirerek toplumları değiştirir ve geliştirir. Dijital teknolojiler; sosyal, ekonomik ve kültürel hayatın hemen her yönüne sirayet ettiği gibi emek piyasalarına da etki etmektedir (ILO, 2015). Bu yeni teknolojilerin verimli bir şekilde kullanılması toplumların en çok dikkat etmesi gereken konuların başında gelmektedir. Zira İşgücünü insanların yararlı şeyler üretmek üzere harekete geçirmek, kullanmak zorunda oldukları fiziksel ve düşünsel yetilerinin tümü olarak tanımlayabiliriz (Özkaplan, 1999; Grinth, 2005).

Bu tanımdan hareketle dijital teknolojiler güncel teknik bilgi ve becerilerin yanında idrak etme, bilişsel düşünme, yaratıcı düşünme, problem çözebilme gibi düşünsel becerilerle donatılmış bireylere ihtiyaç duyduğu söylenebilir. (OECD, 2017). Yeni dönüşümler, bunlara ayak uydurabilecek yeni vasıflı işgücü gerektirir.

Oyun sektörü içerisinde oldukça farklı iş kollarından vasıflı işgücü temsilcileri bir araya gelmektedir: geliştiriciler (Geliştiricilerde oyun tasarımı, görsel tasarım, programlama, modelleme, bölüm tasarımı, test vb.), yayıncılar, dağıtıcılar, perakendeciler, yatırımcılar, fikri mülkiyet sahipleri, hukukçular, platform ya da donanım üreticileri ve pazarlama birimi... vb. Oyun geliştirme oldukça yaratıcı unsurlar ve işbirlikleri gerektiren bir süreçtir (Bkz. Şekil 1). İçerisinde kültürel, sanatsal ve ekonomik öğeler bulundurur (Zackariasson ve Wilson, 2012). $\mathrm{Bu}$ öğelerin başarılı bir şekilde bir arada çalışması ortaya çıkacak ürünün kalitesi ve başarısı için oldukça önemlidir. 
Diğer bir deyişle, tek bir ürün için farklı disiplinler beraber çalışmaktadır: Oyun tasarımı, görsel tasarım, programlama, modelleme, bölüm tasarımı, test ve pazarlama. Ana aktör geliştirici olarak gözükse de, farklı aktörler uygun ve çekici bir ürün için bir arada çalışmaktadırlar.

\section{Şekil-1 Oyun süretim süreçleri}
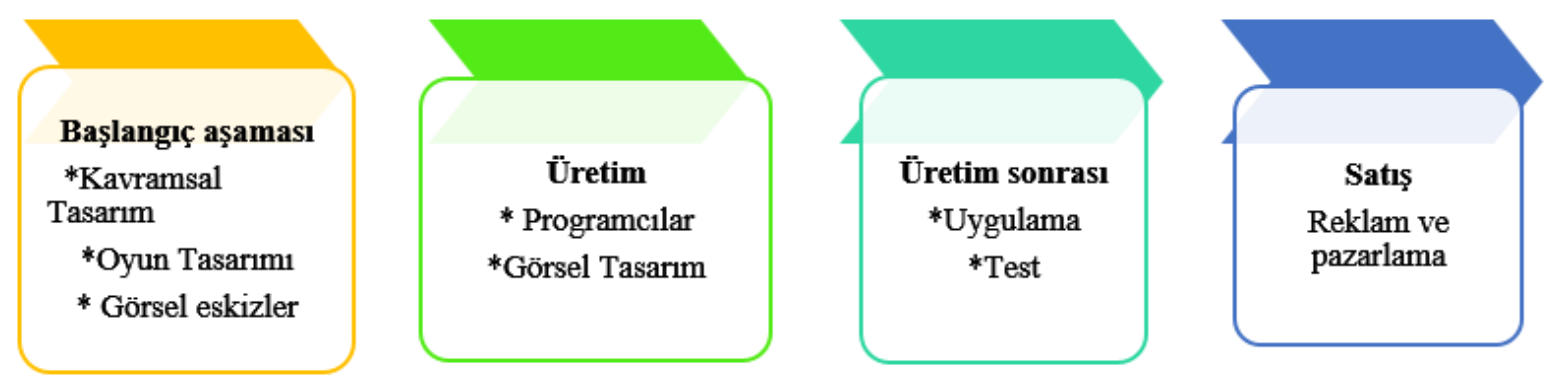

Kaynak: Shah, 2005; Kerr, 2006; Zackariasson ve Wilson, 2012 kaynaklarından yazar tarafindan derlenmiştir.

Görüldüğü üzere çok farklı süreçler için farklı yetenekler gerekmektedir. Ancak mikro ölçekli işletmelerde, tüm bu süreçler için ayrı ayrı çalışan istihdamı mümkün olamamaktadır. Bu tip girişimlerde firma ortakları hem yönetici hem de üretici olarak çalışmaktadır. Ancak bu firmanın verimini azaltan bir sonuç ortaya koymaktadır. Daha büyük firmalarda ise aynı anda birçok proje yürütülebilmektedir. Ancak her projeye uygun nitelikte çalışan bulunmamakta ve sorunu kendi içlerinde farklı uzmanlıkları olan kişilerle çözmektedirler. Bu da çalışma verimini azalmaktadır (ODTÜ TEKNOKENT, 2012).

Türkiye'de geliştirilen oyunların hemen hemen tümü yurt dışı piyasalarda pazarlanmaktadır. Bu sektörde yer almak isteyen yeni bireysel oyun geliştiricileri ve şirketler, özelikle sosyal ve mobil oyunlar sayesinde piyasaya çok rahat giriş sağlayabilmektedirler (Akçetin vd, 2017) . Ancak bu durum rekabeti de arttırmaktadır. Rekabette başarı için doğru ekip doğru proje uyumu gerekir. Bu bağlamda vasıfları yüksek çalışan profili firmalar için önemli bir konudur. 


\section{Dünya'da ve Türkiye'de dijital oyun sektörü ve önemi}

Gelişmiş ülkelerde son yıllarda enformasyon ve iletişim teknolojisi sektörlerinde ortaya çıkan değişmeler, toplumsal, ekonomik ve kültürel düzlemlerde doğrudan ya da dolaylı olarak çeşitli etkiler yaratmaktadır.

Toplumların gelişim talepleri bunu sağlayacak teknolojilerin sürekli geliştirilmesine yol açar. Bu açıdan bilgi, daha önce benzeri görülmedik ölçüde teknik yenilenmeyi ve sosyo-ekonomik büyümeyi sadece yönetmekle kalmamakta, kendisi de hızla ekonominin temel faaliyeti ve mesleki değişimin temel belirleyicisi haline gelmektedir (Kumar, 1999, 24). Bilgiyi ve dijital teknolojileri benimseyen toplumlar; üretimde, ticarette, hizmetlerin kalitesinde ve kişilerin refah düzeylerinin yükseltilmesinde önemli ilerlemeler sağlayabilmektedirler.

Dijital oyunların en büyük özelliği, herhangi bir döneme hâkim olan tüm teknolojilerin içerisinde yer alabilmesidir. 1980'lerle beraber kişisel bilgisayarlar, 1990'larla beraber internet, 2000'li yıllarla da akıllı telefonlar piyasaya çıktıkları zaman insanları çok etkilediler ve dijital oyunlar bu teknolojilerin içerisinde hep vardı. Özellikle, bilgisayarlardaki işlemcilerin ve kartların kalitesinin artmasıyla da dijital oyun sektörünün gelişimi çok hızlandı. Bu dinamik yapının arkasında, ayrıca sürekli gelişen farklı taleplere göre farklı platform arzları, sürekli gelişen oyun içerikleri ve neredeyse her yaşa uygun farklı kitlelere hitap edebilecek oyunların piyasaya sürülebilmesi yatar (Zackariasson ve Wilson, 2012). Bu açılardan baktığınızda, bu sektörde faaliyet gösteren firmaların yenilikçi yönleri ortaya çıkar. Çünkü sektördeki rekabet gereği, hem hizmetlerde, hem de ürün içeriklerinde sürekli yenilik yapmak durumundadırlar.

Konsollar ise sadece oyun deneyimini geliştirmekle kalmayıp, oyunu bir multimedya eğlence ve iletişim aracı haline dönüştürmüşlerdir. Aynı zamanda, günümüzde AAA olarak sınıflandırılan oyunlar, yapım ve maliyet açılarından büyük film prodüksiyonlarıyla kıyaslanır hale gelmiştir. Bu tür oyun projeleri, ses, programlama, animasyon, grafik, pazarlama, tasarım ve yapım gibi farklı alanlarda yüzlerce uzmanı içeren kadrolarla geliştirilmektedir. Dolayısıyla, oyun geliştirme oldukça karışık ve büyük ölçekli bir yapım pratiğine dönüşmüştür. (AKA, 2016).

Her sene milyonlarca insan, milyonlarca doları dijital oyunlara isteyerek ödemektedir. Satılan oyun sayısının artması demek, sektörde dönen finansal aracın da artması anlamına gelmektedir (Egenfeldt-Nielsen, Smith, ve Tosca, 2008). Dijital oyunlar ekonomiyle yakından ilgilidir. Yaratıcı Endüstrilerin en önemli ürünlerinden biridir. Vergi politikasıyla yakından ilgilidir. Eğitim sistemiyle yakından ilgilidir. Oyunlar kültürle iç içedir ve kültür endüstrisinin ürünleridir (Kerr, 2006; Binark ve Bayraktutan Sütçü, 2008; Dymek, 2010). Ulusal kültür, geliştirici kültürü, oyuncu kültürü, anime kültürü; gelenekler, tarih, politika ve benzeri tüm unsurların hepsi, oyunları etkileyen unsurlardır. Diğer bir deyişle ülkelerin kültürel ve sosyal içerikleri oyun tasarımlarını etkileyen en önemli unsurdur. (O’Donnell, 2012).

Oyunlar kültürel yaşamın, sosyalizasyon sürecinin en temel aktörlerinden bir tanesidir. Oyunla toplumsallaşan kitlelerin dijital ortamlardaki sınırsız dünya ve çekici konularla oluşturulan ve buna da çok fazla eğlence unsurları katılmış ürünleri talep etmesi normaldir.

Dijital oyunlarla ve sanal mecralarla ilgili yapılan çalışmalarda oyuncuların reel gündelik yaşamlarındaki habituslarını sanalda/dijitalde de yeniden konumlandırdıkları görülmektedir. Böylece benzer beğenilere sahip oyuncu/tüketiciler bir araya gelmektedir (Binark ve Bayraktutan-Sütçü, 2009: s.277). Ayrıca gündelik yaşamın uzamı genişlemiş olmaktadır ve 
gerek oynama edimi, gerekse de piyasanın varlığı bu uzamda kendisine hareket alanı bulmaktadır. Sanal kimlik gerçek kimliğin bir uzantısıdır. Başka bir ifadeyle gündelik kimlik öğeleri sanal uzamda da temsil edilir (Binark ve Bayraktutan-Sütçü, 2008: s.56-57).

Sonuçta, teknolojinin hızla gelişmesi oyunları kitleler için kullanabilir hale getirmiş ve bunun sonucunda da dijital oyun sanayii en hızıı büyüyen sektörlerden biri olmuştur. Bu gelişmenin diğer alanlara da pozitif etkisi olmuştur. Örneğin tıp eğitiminde, sağllk eğitiminde, kültürel varlıkların sunumunda ya da örgün eğitimde animasyonların kullanımı, oyunların özellikle de oyunlaştırma kavramının altında kullanılır olmuştur. Son yıllarda da arttırılmış gerçeklik ve sanal gerçeklik teknolojileri ve uygulamaları, ayrıca etkileşimli sistemler de bu sektörlere paralel olarak katılmış, ivme hızla artmıştır.

Dünya genelinde 2,69 milyar dijital oyun oynayan kişi mevcuttur https://www.statista.com/statistics/293304/number-video-gamers/). 2019 y1l sonunda oyun piyasası toplam 153 milyar dolara ulaştı. Son 10 yıllık gelişim trendi incelendiğinde, yıllık yüzde 8'lik bir büyüme olduğu görülmektedir (Tablo 1). 2023 yllında büyüklüğün 200 milyar doları aşacağı öngörülmektedir. Mobil oyunların payı ise yüzde 50 olacaktır (Newzoo,2020).

\section{Tablo 1- Küresel dijital oyun sektörü gelirleri}

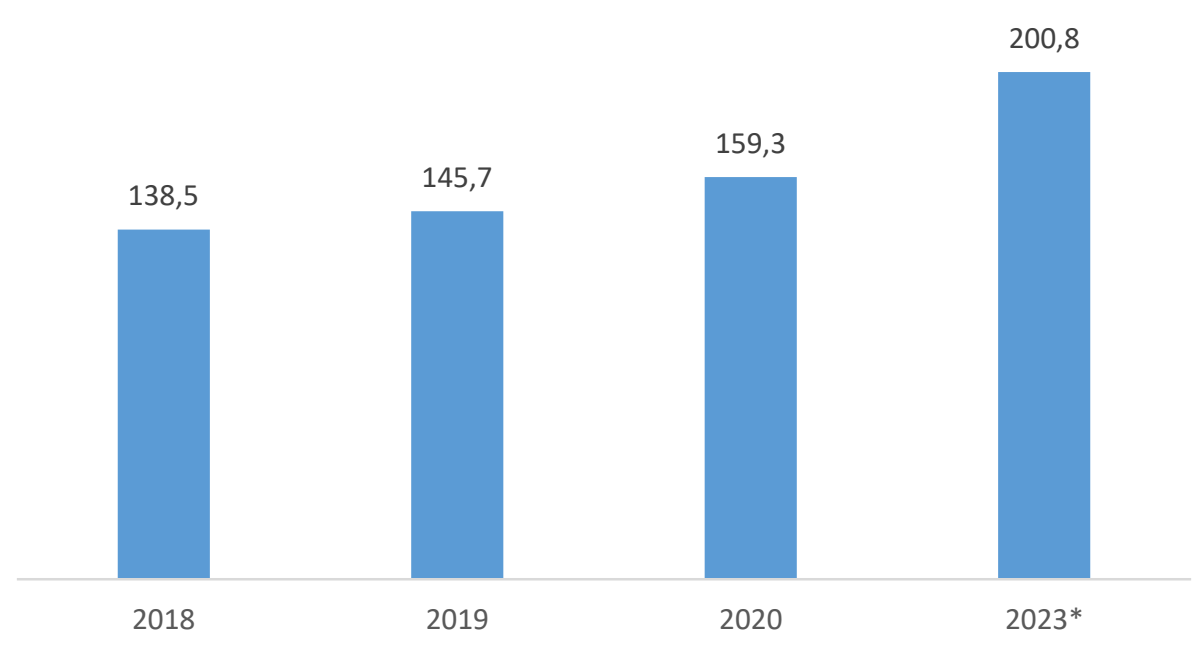

Kaynak: www.newzoo.com

Türkiye Bilgi Toplumu Stratejisi 2015-2018'de oyun sektörünün ülkede geliştirilmesini hedeflemiş̧irr. Stratejiye göre, bireysel yazılım pazarında büyümeyi mobil uygulamalar ve oyun pazarı sürdürecektir (BİTD, 2015). Türkiye'nin 2023 hedefleri doğrultusunda hazırlanan 10. ve 11. Kalkınma Planlarında Türkiye'nin "üretim ve ihracatta yüksek katma değerli ve teknoloji yoğun bir yapıya kavuşması için yapısal bir dönüşüm ihtiyacı bulunduğu belirtilmektedir (SBB, 2013; 2018). Mobil uygulama ve dijital oyunlarda erken aşama girişimlerin arttı̆̆ vurgusu yapılarak bu çalışmaların desteklenmesi ve özellikle de bilgi teknolojileri alanında nitelikli çalışanlara ihtiyaç duyulmaktadır.

Türkiye dijital oyunlar açısından oldukça önemli bir pazar haline gelmektedir. 80 milyonu aşan nüfusu ile internet, sosyal medya ve diğer dijital platformlar yoğun bir şekilde kullanılmaktadır. $\mathrm{Bu}$ durum dijital oyunlara da yansımışıtır. 
Türkiye İstatistik Kurumu'nun (TÜIK) 2020 y1lı rakamlarına göre Türkiye'de internet kullanan bireylerin oranı yüzde 79'a ulaşmıştır. Bu rakam sadece iki yıl önce 72,9'du. Bilgisayar kullananların oranı ise yüzde 59,6'dır Genişbant ile internete erişim sağlayan hanelerin oranı 2018 yılı Nisan ayında yüzde 90 olmuştur. Buna göre hanelerin yüzde 89'u sabit genişbant bağlantı (ADSL, kablolu İnternet, fiber vb.) ile İnternete erişim sağlayabiliyor. Bu rakam da sadece 2 sene önce yüzde 45.2’ler civarındaydı (TÜIK, 2020).

Öte yandan yetişkin insanların \%98'i cep telefonu kullanırken, bunların \%90'1 akıllı telefon kullanıyor. Masaüstü bilgisayar veya dizüstü kullananların oranı $\% 76$ iken, tablet kullananların oranı \%59 (Deloitte, 2019). Bu rakamlardan anlaşılacağı üzere mobil cihazların kullanım oranı oldukça yüksek ve geçen seneye göre kullanım oranlarında artış var. Rapora göre Türkiye'de toplam 53 milyon sosyal medya kullanıcisı var ve bu kullanıciların $\mathbf{4 4}$ milyonu mobil cihazlar ile sosyal medyaya bağlanıyorlar. Bu kişilerin mobil cihazlarını en çok kullanım amaçlarının başında oyun oynamak geliyor (Deloitte, 2019). Öte yandan Türkiye'de tüm platformları düşündüğümüzde dijital oyun oynayanların sayısı 32 milyondur. Bu oyuncuların yarattığı ekonomi ise 800 bin dolar civarındadır (Gaming Turkey, 2019). Öte yandan TOGED verilerine göre ülke firmalarının ihracatı 2019 yllında 1 milyar dolar seviyesini aştı. Türkiye'deki genç nüfusun büyüklüğü, çevrim içi konsol oyunları, mobil/tablet oyunlar ve sosyal oyunlara olan talebi her geçen gün artırmaktadır (AKA, 2016). Bu rakamlara göre Türkiye dünya pazarında 18. sırada bulunmaktadır. (Gaming Turkey, 2019).

Oyun oynama süresi ve oyuncu sayısının nüfusa oranı gibi sıralamalarda dünya listesi zirvesinde olan Türkiye'nin bu önemli potansiyelini hayata geçirebilmesi için oyun sektörü stratejisini sağlıklı bir şekilde oluşturması ve hedefe yönelik eylemlerle ilerlemesi gerekmektedir.

Öte yandan, Türkiye'de oyun geliştiren firmaların sayısı hızla artmaktadır. Ancak kesin sayısını referans alabileceğimiz resmi kaynak yoktur. ODTÜ Teknokent'in 2012 raporuna göre dijital oyun firma sayısı 22 iken bu sayı günümüzde StatupsWatch'un verilerine 239'dur (startupswatch.com). Bu rakamlar bile Türkiye'de üretim gücünün nasıl arttığını anlamamızı sağlamaktadır.

Dijital oyunun piyasaya sunulması için programlama, sanat, ses, tasarım, satış, pazarlama, reklam, planlama ve yönetim ekibine ihtiyaç vardır. Oyun geliştirici profili, bireysel geliştiricilerden 50-100 kişilik büyük ekiplere kadar yayılan bir yelpazede olsa da, büyük çoğunluğunu 10 kişi civarında çalsşanın oluşturduğu mikro ölçekli girişim profili vardır (Kepenek, 2018). En kalabalık firmanın 115 çalışanı vardır ve bu kadar çok çalışanı olan başka firma yoktur. Türkiye'de oyun geliştirme alanının önemli bir özelliği, henüz şirketleşmemiş ekip ve bireylerin de oyun geliştirme alanında aktif olarak rol almasıdır. Üretim anlamında oyun sektörü Ankara ve İstanbul illerinde yoğunlaşmıştır. Medya ve pazarlama firmaları ise, esas olarak İstanbul'da yoğunlaşmıştır. Firmaların ekip sayıları 20 'den fazla olan firmaların oranı \%3’tür. (AKA, 2016).

\section{Araştırmanın yöntemi}

Araştırma iki aşamalı olarak tasarlanmıştır. İlk aşamada, ikincil kaynaklardan yararlanılarak bir literatür taraması yapılmıştır. Bu sayede makalenin temel bakış açısı oluşturulmuştur. İkinci aşama ise alan araştırmasıdır. Bunun için öncelikle yarı-yapılandırılmış soru formu hazırlanmıştır. Araştırmanın evreni Türkiye'deki dijital oyun geliştiren firmalar olarak belirlenmiş ancak daha sağlıklı analiz yapmak için örneklem çıkarılmıştır. Türkiye'de ne kadar 
firma olduğuna dair kesin bir bilgi kaynağı olmadığı için, TOGED üyeleri görüşme yapılacak firmalar olarak belirlenmiştir. Çalışmanın gerçekleştirildiği zaman Derneğin 30 firması vardı ve hepsi ile yüzyüze ve internat ortamında görüşmeler gerçekleştirildi. Görüşmeler firma ortakları, proje yöneticileri ya da üst düzey oyum tasarımcıları (lead game designer) ile gerçekleştirilmiştir. Görüşmeler 2019 yılı Eylül- Aralık ayları arasında gerçekleştirilmiştir. Politika önerileri de firmalarla yapılan görüşmeler sonucunda elde edilen bulgulara göre oluşturulmuştur.

\section{Alan Araştırması}

Bu araştırma TOGED üyesi 30 firma ile görüşmeler yapılarak gerçekleştirilmiştir. Tüm firmalar Türkiye'de faaliyet göstermektedir.

\subsection{Genel görünüm}

Firmaların sadece 4 tanesi 2010 yılından önce kurulmuştur. 5 tanesi 2010-2015 yılları arasında. Geri kalanlar ise 2015 ve sonrasında kurulan firmalardır. Sadece bir firma dişındakiler en az 2 ortakla kurulmuş firmalardır. Bu kadar genç ve ortaklı yapıyla kurulan firmaların, erken aşama girişimciler olduğu anlayabiliyorız.

Firmaların 14 tanesi Ankara'da, 11 tanesi İstanbul'da, 5 tanesi İzmir'de, faaliyet göstermektedir. Tüm firmalar oyun geliştirme yapmaktadırlar. Buna ek olarak farklı gelir kalemleri kullanan firmalar da mevcuttur. 6 firma oyun yayıncılığı da yapmaktadır.Bu firmaların yüzde 85 'i mobil oyun yapmaktadır. Bunu yüzde 28,6 ile PC oyunları takip etmektedir.

Tablo 2- Oyun türlerine göre geliştirici firmalar

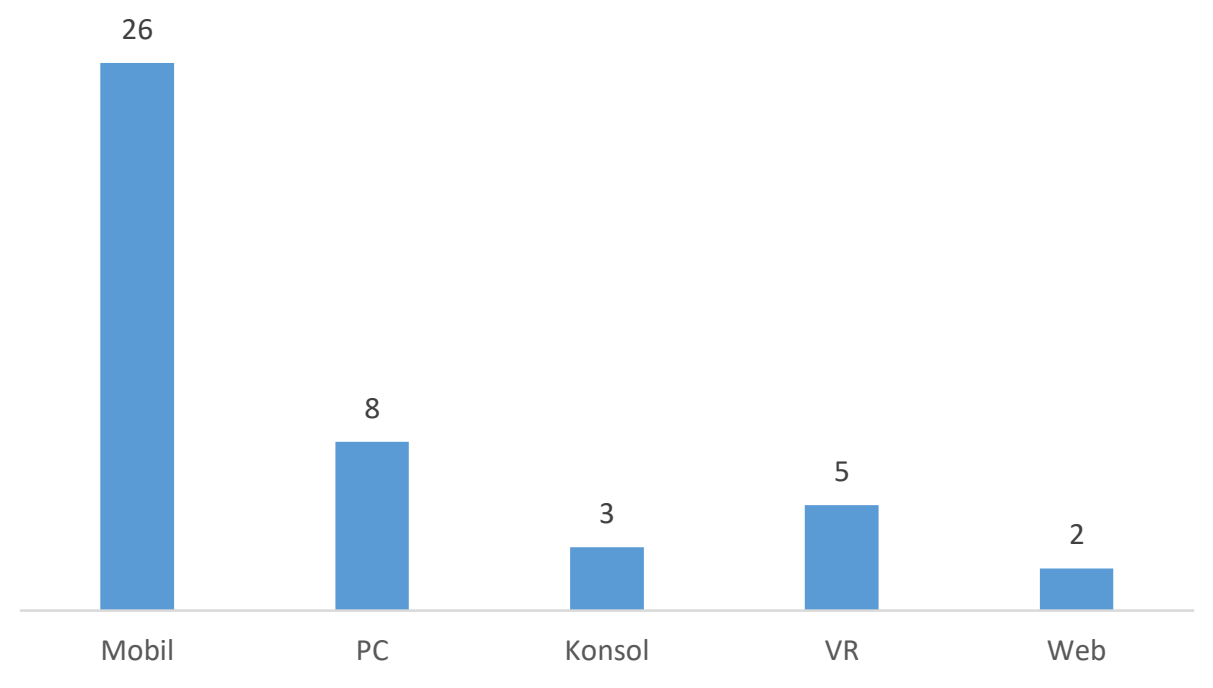

En çok geliştirilen oyun türü ise yüzde 84 ile mobil oyunlar. Onun içerisinde de yüzde 48 ile Hyper-casual adı verilen son dönemin en trend oyun türü ağırlıkta. Türkiye'deki sektörün dünya trendlerini yakından takip ettiği söylenebilir. Hyper casual oyunların üretim süreçleri de hızlı olduğu için bir yıl içerisinde 30'dan fazla oyun geliştiren firmalar oldukça fazla. Midcore oyun (zorluk derecesi ve seviyeleri daha fazla olan oyunlar) geliştiren firmaların yılda yaptıkları 
üretim adedi 1 ya da 2 oluyor. Oyun satış kanalları üzerinde, iki büyük mobil teknoloji firmasının, mobil uygulama satış kanallarının yüzde 91 oranda ağırlığı var.

\section{2.İşgücü profili}

Görüşülen 30 firmada toplam 390 çalışan vardır. Ancak sadece bir firmada 115 çalışan vardır. O firmayı dışarıda bıraktığımızda, 29 firmada ortalama 9 çalışan vardır. Bu bağlamda Türkiye'deki dijital oyun firmalarının mikro ölçekli işletme oldukları söylenebilir. Toplam çalışanların yüzde 20'si kadın çalışanlardan oluşmaktadır. Dünya ortalaması yüzde 22 olduğu düşünüldüğünde ortalamaya yakın bir oran olduğu söylenebilir. Tüm çalışanların sadece yüzde 14'ü yönetim ve idari kadroyu oluşturmaktadır. Geri kalan çalışanların hepsi oyun geliştirme süreçlerinde görev almaktadırlar. Firmaların yüzde 80'ninde kurucu ortaklar, hem üretimde yer almaktadır hem de yönetim işlerini beraber yürütmektedirler.

Çalışanların yüzde 90'1 üniversite mezunudur. Çoğunlukla da üniversitelerin Bilgisayar Mühendislikleri ve Görsel Tasarım bölümlerinden mezun oldukları görülmektedir.

Firmaların yüzde 97'si nitelikli işgücü bulmada sorun yaşadıklarını belirtmişlerdir. Bu da makalenin yazım amacıyla uyuşan bir göstergedir. En çok sorun yaşanılan alan ise yüzde 74 ile programlamadır. Daha sonra yüzde 55 ile pazarlama gelmektedir. Yüzde 44 ile oyun tasarımı ve görsel tasarım gelmektedir. Firmaların yüzde 68 'si, pazarlama ve oyun tasarımı konusunda eğitim olanakları olsa, çalışanlarını eğitime gönderebileceklerini belirtmiştir. Ve bu firmaların yüzde 91'i, Türkiye'de dijitaloyun sektörü için yeterli eğitim olanağı olmadığını belirtmiştir.

\section{Tablo- 3 Firmaların yaşadıkları problemler (Yüzde)}

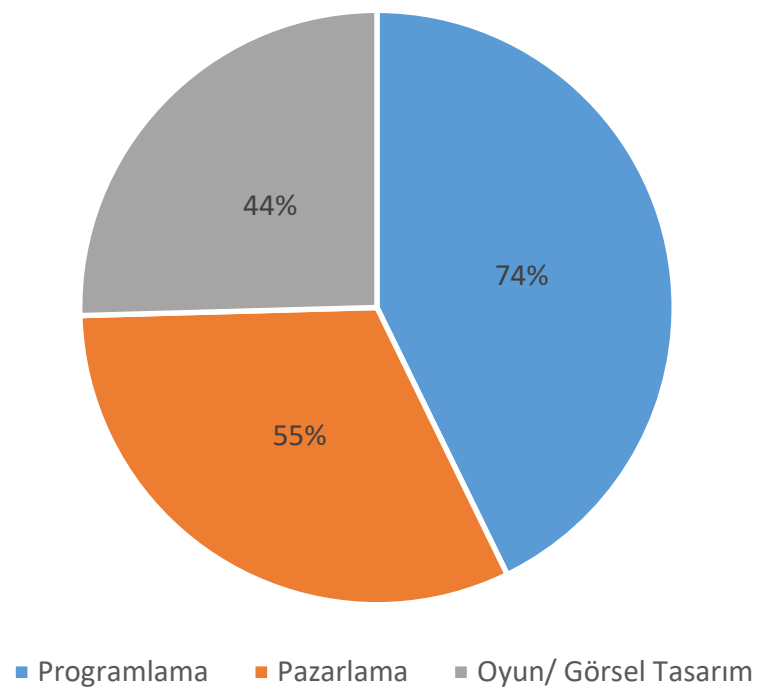

\subsection{Yenilik ve işbirliği}

Oyun geliştirme süreçlerinde bahsedildiği gibi, oyun üretimi sonrasında test ve pazarlama süreçlerinin olduğu en son aşama gelir. Bu aşamada finansal tabloların çok iyi analiz edilmesi gerekir. $\mathrm{Bu}$ konu, dijital oyun firmalarının başka firmalarla işbirliğini tercih ettikleri bir aşamadır. Oyun firmalarının yüzde 84'ü, bu anlamda dışarıdan hizmet alma yolunu tercih etmektedirler. $\mathrm{Bu}$ alanda uzmanlaşmış firmalar geliştirdikleri yazılım araçları ile bu hizmeti vermektedirler. Geri kalan firmalar ise (yüzde 16) oyunlarının test analizlerini, kendi 
geliştirdikleri yazılımlar üzerinden yapmaktadırlar. Bu alanda kendi yeteneklerini geliştirme ve organziasyonlarında yenilik yapmayı tercih etmişlerdir. Bütün firmalar ihtiyacı olan vasıflı personeli bulması halinde dışarıdan hizmet almayabileceğini belirtmişlerdir. $\mathrm{Bu}$ talep dijital oyun sektöründe çalışmak isteyecek genç beyinler için önemli istihdam firsatları sunmaktadır. Firmaların yüzde 60'ı oyun geliştirme süreçlerinde de dış unsurlarla işbirliği yapmayı tercih etmektedirler. $\mathrm{Bu}$ alanda yüzde 44 ile görsel tasarım desteği öne çıkmaktadır. $\mathrm{Bu}$ aşamada serbest çalışan sanatçılarla çalışılmaktadır. Ancak firmaların yüzde 60'1 oyunları yayınlamak için başka firmalarla çalışmayı tercih etmektedirler. Yayıncılık, dijital oyun sektörü için önemli alt kırılımlardan bir tanesidir. Firmaların bu konuda kapasiteleri eksiktir. Dışarıdan hizmet alma nedenlerine bakıldığında, en önemli neden olarak firmaların ihtiyaç duydukları alanlarda gerekli vasıflı işgücü bulamamaları görülmektedir. (\% 100) İkinci sırada üretim maliyetlerini düşürmek gelmektedir (\%37).

Firmaların yüzde 32'si oyun geliştirme süreçleri için dışarıdan danışman desteği de almaktadır. Özellikle test analizleri, içerik geliştirme ve firma içi iletişim konularında danışmanlıklar alınmaktadır. Bu süreçlerle ilgili olarak fïmaların tamamı, dünyadaki gelişmeleri ve diğer firmaları yakından takip ettiklerini belirtmişlerdir.

\section{Dijital oyun sektöründe işgücü sorunununa yönelik politika önerileri}

Her ne kadar çok boyutlu bir endüstri olsa da, bu bölümde sadece nitelikli işgücünün yetiştirilmesine yönelik fikirler paylaşılmıştır. Her alanda olduğu gibi nitelikli işgücü yetiştirmenin temel aracı eğitimdir. Türkiye'de sadece 4 üniversitede dijital oyun tasarımı lisans ve 3 üniversitede de yüksek lisans programları mevcuttur. Bu durum büyüme potansiyeli son derece yüksek olan dijital oyun sektörü için oldukça yetersizdir. Ayrıca, Türkiye'de neredeyse tüm üniversitelerde Bilgisayar Mühendisliği, Görsel Tasarım ve İşletme vb bölümler olsa da, sektör firmalarının yıllardır nitelikli işgücü sıkıntısı çekmesi tartışılması gereken başka bir konudur. Bu bağlamda kamu politikaları ile endüstrinin aktörleri arasında uyumsuzluk olduğu söylenebilir.

Artan kapitalist rekabet, ülkelerin daha fazla teknolojiye ve ekonomik değeri yüksek yenilikçi sektörlere doğru adım atmalarına yol açmaktadır. Ülkeler öncelikle dijital dönüşümün etkilerini ve olası sonuçları belirlemeli, ardındanona göre politikalar geliştirmelidirler. Dijital ekonominin en önemli ürünlerinden biri olan dijital oyunlar için de, bu bağlamda çalışmalar yapılması gerekmektedir. Bu durum Türkiye'nin planlama çalışmalarında da (Vizyon 2023, 11. Kalkınma Planı vb) kendini göstermektedir: "Teknolojiyi yönlendiren; yetkin beşeri sermayeye sahip; üniversite, özel sektör, STK ve kamu işbirliği ortamında teknolojiyi yöneten, dijital ürün ve hizmet geliştiren, sürdürülebilir, kapsayıcı ve rekabetçi bir dijital ekonomiye ulaşmak." önemli hedeflerden bir tanesidir.

Dünya pazarı incelendiğinde, başarılı ülke örneklerine bakıldığında, başarılı sektörlerin arkasında mutlaka tarihsel ve kültürel bir doku olduğu görülür. Yani sektörel başarının arkasında tarihsel süreç boyunca oluşmuş kültür ve yapı var. Ve o ülkeler bu kazanımı, ulusal politika ve kurumlarla desteklemektedirler. Örneğin, Güney Kore'nin önemli ajansı KOCCA 1978 yılında kuruldu. Ajans tüm dünyada Güney Kore firmalarının pazarlanmasında, destekler sağlıyor ve firmaların sektörel eğitimlerine destek oluyor. Altında zaman içerisinde oluşan derin bir kültür, politika hedefi ve bu hedefe göre kurgulanmış bir eğitim sistemi vardır (Aoyama\& Izushi, 2003). 
Bu eğitim politikası, mutlaka mevcut mesleklerdeki değişimi ve ortaya çıkacak yeni meslekleri de teknolojilerdeki gelişmelerle izlemek ve değerlendirmek gereklidir. Bu nedenle bilimsel bir bakış açısıyla kurgulanmış yeni bir kamusal kurum oluşturulması faydalı olacaktır. Bu sayede, dijital oyun endüstrisindeki rekabette var olabilmek için, beşeri sermayenin mesleki yeterliliklerinin yeni mesleki ihtiyaçlara uyumu sağlanabilecektir.

Buna yönelik olarak;

Eğitim Öğretim kurumları müfredatlarının içeriklerinin güncellenmesi ve dijital oyun üretim süreçlerinin eğitim-öğretim hayatının tüm aşamalarına konulması faydalı olacaktır. Bu içeriğin sağlanması için sektörün tüm boyutlarıyla bir resminin çekilmesi, bir veri tabanı oluşturulması gerekir. Böylece eğitim ihtiyaçları daha düzgün bir şekilde belirlenebilecektir. Bu sürece sektör firmalarının dahil edilmesi elzemdir. Onların ihtiyaçlarına göre güncelleme yapılabilir.

Beceri havuzu oluşturarak istihdam ekosisteminin canlandırılması gereklidir. Ayrıca bu alanda bireylerin eleştirel düşünme, analitik düşünme, sanatsal düşünme ve problem çözme becerlerini geliştiren, değişime adapte olabilen, yaratıı, Ar-Ge kültürünü içselleştirmiş, tasarım odaklı çalşsabilen ve teknolojiyi kullanmanın yanında geliştirebilme yeteneğine sahip olmalarının sağlanması için eğitim olanaklarının düzenlenmesi gerekir.

Türkiye'nin dijital oyun sektöründeki hak ettiği yeri alabilmesi için bu sektörün yapısı ve ihtiyaçlarına yönelik yeni destek programlarının bir an önce oluşturulması gerekmektedir. Sürdürülebilir ve uzmanlaşmış iş ve kuluçka modellerinin geliştirilmesi ve oyun sektöründeki yenilikçi eğilimleri takip ederek, buna göre niteliki işgücü yetiştirme programlarının kurulması gereklidir.

\section{Sonuç}

Dijital oyunların en büyük özelliği, herhangi bir döneme hâkim olan tüm teknolojilerin içerisinde yer alabilmesidir. 1980'lerle beraber kişisel bilgisayarlar, 1990'la beraber internet, 2000 'li yıllarda akıllı telefonlar piyasaya çıktıkları dönemlerde insanları çok etkilediler ama dijital oyunlar bu teknolojilerin içerisinde hep vard. Dijital oyun endüstrisi 1980'lerden itibaren hızla büyümektedir. Teknolojik gelişmelerin desteğiyle dijital oyunlar dünya nüfusunun dörtte birini etkisi altına almıştır. Türkiye yarattığ 1 katma değer ile dünyada 18 . sırada yer almaktadır. Oyun geliştirici profili, bireysel geliştiricilerden 50-100 kişilik büyük ekiplere kadar yayılan bir yelpazede olsa da büyük çoğunluğunu 10 kişi civarında çalışanın oluşturduğu mikro ölçekli girişim profili vardır.

Dijital oyunların üretim süreçleri programlama, sanat, ses, tasarım, satış, pazarlama, reklam, planlama ve yönetim vb. çok farklı uzmanlık alanları gerektirmektedir. Görsel ve yazılımsal kurguların yoğun olarak kullanıldığı bu sektörde nitelikli işgücü talebi her geçen gün artmaktadır. Çünkü endüstri hızla büyümektedir. Ancak bu talebi karşılayacak kaynak yoktur. Yapılan araştırmalar, Türkiye dijital oyun endüstrisinde faaliyet gösteren firmaların karşılaş̧ıkları en büyük sorunun uygun nitelikte çalışan eksikliğidir. Türkiye, genç ve dinamik nüfus yapısına sahiptir. Bu genç nüfus, yeni dijital dönüşüme kolayca adapte olabilecek kişiler olarak görülebilir ancak var olan eğitim sistemi firmaların ihtiyaçlarına cevap verecek nitelikte değildir.

O nedenle eğitim müfredatının dijital oyun sektörünün geleceği göz önüne alınarak bir planlama ve hedef içerisinde yeniden düzenlenmesi şarttır. Bunu yaparken, oyun firmaları sürece dahil 
Kepenek, E. B. (2020), “Türkiye Dijital Oyun Sektöründe Nitelikli İşgücü Sorunsalı: Sosyo-Ekonomik Bir Bakış”, Politik Ekonomik Kuram, 4 (2), 296-309.

edilmelidirler. Nitelikli işgücüne olan talebin karşılanamaması bir problem olsa da sektörün yüksek istihdam potansiyeli olduğunu gösterir. O nedenle gençlerin kendilerini farklı uzmanlık alanlarına geliştirmeleri gerekir.

\section{Kaynakça}

Akçetin, E. 2017. Dijital Oyunlar ve İstihdam: Türkiye için Öneriler. Girişimcilik İnovasyon ve Pazarlama Dergisi. 1(2), sf. 136-153.

Ankara Kalkınma Ajansı (AKA). 2016. Dijital Oyun Sektörü Raporu. http://www.ankaraka.org.tr/archive/files/yayinlar/ankaraka-dijital-oyun-sektoru.pdf (Erişim: 22.09.2020).

Aoyama, Y. ve Izushi, H. 2003. "Hardware Gimmick or Cultural Innovation? Technological, Cultural, And Social Foundations Of The Japanese Video Game Industry". Research Policy, 32(3): 423-444.

Bergonse, R. 2017. Fifty Years on, What exactly is a videogame? An Essentialistic Definitional Approach. The Computer Games Journal. 6(4), sf: 239-255.

Bryce, J. ve Rutter,J. 2006. Understanding Digital Games. London: Sage Publications.

Bilgi ve İletişim Teknolojileri Kurumu (BTK).2017. Dijital Oyunlar Raporu. https://www.guvenliweb.org.tr/dosya/82MsL.pdf (Erişim Tarihi: 22.09.2020).

Binark, M. ve Bayraktutan Sütçü, G. 2008. Kültür Endüstrisi Ürünü Olarak Dijital Oyun. İstanbul: Kalkedon Yayınları.

Castells, M.2011. Enformasyon Çă̆ı. (Çev. Ebru Kılıç).İstanbul: Bilgi Üniversitesi Yayınları.

Deloitte. 2019.Deloitte Global Mobil Kullanıcı Araştırması.

https://www2.deloitte.com/tr/tr/pages/technology-media-andtelecommunications/articles/global-mobile-consumer-survey.html (Erişim Tarihi: 02.10.2020)

Dymek, M. 2010. Industrial Phantasmagoria: Subcultural Interactive Cinema Meets Mass Cultural Media of Simulation" http://www.diva-portal.org/smash/get/diva2:320752/ FULLTEXT01.pdf (Erişim Tarihi: 15.09.2020).

Egenfeldt-Nielsen, S., Smith, J. H. ve Tosca, S. P. 2015. Understanding video games: The essential introduction. London: Routledge.

Gaming Turkey. 2019. Türkiye Oyun Sektörü Raporu.

https://www.slideshare.net/GaminginTurkey/turkiye-oyun-sektoru-raporu-2019-

229041734 (Erişim Tarihi: 27.09.2020).

Grinth, K.2005. The Sociology of Work: An Introduction. London: Polity Press.

Huizinga, J. 2013. Homo Ludens. İstanbul, Turkey: Ayrıntı Yayınları. 
Kepenek, E. B. (2020), “Türkiye Dijital Oyun Sektöründe Nitelikli İşgücü Sorunsalı: Sosyo-Ekonomik Bir Bakış”, Politik Ekonomik Kuram, 4 (2), 296-309.

ILO. (2015a). World Employment Social Outlook: The Changing Nature of Jobs. Geneva. from http://www.ilo.org/wcmsp5/groups/public/---dgreports/---dcomm/-publ/documents/publication/wcms_368626.pdf (Erişim Tarihi: 30.09.2020).

Jethva, K. 2015. Game Development Process - How and How Not To Proceed. http://www.theappguruz.com/blog/game-development-processproceed\#sthash.QlwukQLR.dpuf (Erişim Tarihi: 15.08.2020).

Kepenek,E.B.2018. Entrepreneurial mindset in video gaming sector: Evidence from Turkey.SBF Dergisi. Cilt 73, No. 2, sf. 641 - 664.

Kerr, A. 2006. The Business and Culture of Digital Games. Gamework/ Gameplay. London: Sage Publications.

Kumar, K.1999. Sanayi Sonrası Toplumdan Post-Modern Topluma Çağdaş Dünyanın Yeni Kuramları. Ankara: Dost Kitapevi.

O'Donnell, C. 2012. This is Not a Software Industry. Zackariasson, P. ve Timothy, W. (Der.). The Video Game Industry: Formation, Present State, and Future (sf. 17-33). New York: Routledge.

ODTÜ-TEKNOKENT 2012. Türkiye Dijital Oyun Sektörü Raporu. Ankara.

OECD (2017). OECD Digital Economy Outlook 2017. Paris: OECD Publishing.

Özkaplan,N.1999.İşgücü Piyasasına Ait Kavramların Sorgulanması. Ekonomik Yaklaşım. Cilt 10, Say1 32, Sf. 61-85.

Shah, N. 2005.The video game industry: An industry analysis, from a VC Perspective. http://digitalstrategies.tuck.dartmouth.edu/digital/assets/images/05_shah.pdf (Erişim Tarihi: 27.09.2020).

Türkiye Dijital Oyunlar Federasyonu (TÜDOF). 2012 Ülkemizde ve Dünyada Dijital Oyunlar Genel Raporu. www.tudof.org/?p=411 (Erişim Tarihi: 22.09.2020).

TÜİK. 2020. Hanehalkı Bilişim Teknolojileri İstatistikleri. http://www.tuik.gov.tr/PreTablo.do?alt_id=1028 (Erişim Tarihi: 10.09.2020)

Zackariasson, P. and Timothy W. 2012. The Video Game Industry: Formation, Present State, and Future. New York: Taylor \& Francis.

Newzoo.2020.Global Games Market Report. https://newzoo.com/insights/articles/newzoogames-market-numbers-revenues-and-audience-2020-2023/ (Erişim tarihi: 05.10.2020).

T.C.Cumhurbaşkanlığı Bilgi ve İletişim Dairesi Başkanlığı (DİBD)2015. Bilgi Toplumu Stratejisi ve Eylem Planı 2015-2018. www.bilgitoplumu.gov.tr (Erişim tarihi: 14.08.2020)

T.C.Cumhurbaşkanlığı Strateji ve Bütçe Başkanlığı. 2015. Onuncu Kalkınma Planı. www.sbb.gov.tr (Erişim tarihi: 14.08.2020) 
Kepenek, E. B. (2020), “Türkiye Dijital Oyun Sektöründe Nitelikli İşgücü Sorunsalı: Sosyo-Ekonomik Bir Bakış", Politik Ekonomik Kuram, 4 (2), 296-309.

T.C.Cumhurbaşkanlığı Strateji ve Bütçe Başkanlığı. 2018. Onbirinci Kalkınma Planı. www.sbb.gov.tr (Erişim tarihi: 14.08.2020)

Türkiye Dijital Oyun Firmaları İhracat Rakamı- www.toged.org (Erişim tarihi: 14.12.2019)

Türkiye Dijital Oyun Firmaları Rakamları- www.startsupwatch.com (Erişim tarihi:

01.08.2020) 